\title{
O Tribunal Constitucional Internacional e a modernidade jurídica: um passo adiante e alguns passos atrás
}

\author{
Marcelo Gomes Franco Grillo ${ }^{1}$
}

\begin{abstract}
Resumo: Coloca-se a questão da importância da criação de um Tribunal Constitucional Internacional desde que seja constituído de forma heterogênea, com a inclusão dos países menos desenvolvidos. Além disso, se visa demonstrar que a criação de um Tribunal Constitucional Internacional pode ser um passo adiante, na proteção da dignidade da pessoa humana, dos direitos sociais e dos direitos humanos. Entretanto, aponta-se que a sua defesa e criação não deixa de ser uma retomada de valores jurídicos liberais eminentemente modernos, frente ao desmonte neoliberal do Estado, que ocorre igualmente por meio do direito contemporâneo.

Palavras Chave: Forma Jurídica, Globalização, Direitos Sociais, Dignidade da Pessoa Humana e Cidadania.

Abstract: There is the whole issue of the importance of creating an International Constitutionalist Court as long as its been consisted in an heterogeneous form, with the inclusion of the less developed countries. Besides it, intends to demonstrate that the criation of an International Constitutionalist Court can be a step forward, into the protection of the human dignity, of the social rights and of the human rights. However, it is worth pointing out that its defense and criation doesn't let to be a retaken of the liberal legal values, eminently moderns, ahead of the neoliberal desmounting from the State, which also occurs in the contemporary right.
\end{abstract}

Keywords: Globalization, Social Rights, Human Dignity, Citizenship.

\section{I - Introdução}

Nesses tempos de diluição das fronteiras do Estado, de fruição do direito e do Estado aos mais gritantes interesses do capital, a normatividade jurídica aparece inexoravelmente imbricada a forma-capital para lá de uma relação relativamente menos ideologizada. No iluminismo, se o direito e o Estado apareciam diretamente como expressão da vontade de legislação, vide as codificações do início do século XIX; na atualidade, o panorama dado pelos diversos micros sistemas jurídicos e institucionais aponta para uma complexidade maior na formatação dos ordenamentos jurídicos nacionais. Ideologias e plexos de interesses do capital continuam a formatar o direito e a forma de interpretá-lo. Os confins do direito e das Constituições não estão dados somente no terreno do Estado-nação.

É inegável que a globalização do pensamento jurídico e constitucional, se por um lado envolve forças em direção à realização dos direitos humanos, por outro, é reflexo dos interesses das elites dominantes dos Estados nacionais, em moldes jurídicos que podem lembrar as "razões" do iluminismo, isso exatamente quando há a prevalência dos paradigmas da segurança jurídica e da máxima proteção da propriedade privada, temas caros a todo o pensamento jurídico moderno.

Elites nacionais não mais estão prioritariamente adstritas ao território do Estado-nação. $\mathrm{O}$ capitalismo financeiro e os interesses das multinacionais permeiam qualquer pensamento globalizante que se quer estabelecer ou se tenha estabelecido, ou

\footnotetext{
${ }^{1}$ Doutorando e mestre em Direito Político e Econômico pela Mackenzie, Brasil. Foi pesquisador, com bolsa de estudos de doutoramento, na Faculdade de Direito da Universidade do Porto, Portugal.
} 
pelo menos esse impregnar-se se constitui nas suas funções axiológicas no campo do Estado e do direito.

Nesta quadra, pensar em uma globalização jurídica e constitucional é também pensar em sua razão ontológica. Para a doutrina constitucional, uma pergunta deve colocar-se: quais os pressupostos ideológicos e finalísticos do constitucionalismo que autorizam as mais variadas vontades de constituição, inclusive para além da fronteira do Estado?

Em conjunto com as ideologias e as forças reais de poder (para recuperar uma expressão de Ferdinand Lassalle ${ }^{2}$ ), também as questões da procedimentalização jurídica podem aparecer como um verdadeiro problema na globalização jurídica: tudo a desembocar em agudos dilemas sociais e culturais de convivência. Se por um lado tem-se o Estado - muito no caso da União Europeia - não mais delimitado prioritariamente ou tão somente pela tríade território, povo e soberania, por outro, a institucionalização de novos horizontes organizacionais não aponta para o fechamento dos dilemas sociais e jurídicos contemporâneos.

O constitucionalismo, como gestado pela Revolução Francesa para fundar, ordenar e limitar o poder político e garantir os direitos e as liberdades fundamentais (Canotilho) ainda pode encontrar ressoante coro nas vozes jurídicas contemporâneas mais críticas, mais preocupadas com os reais problemas sociais. É chegado o tempo no qual certo potencial da crítica normativista estaria novamente em defender o constitucionalismo e as constituições (mesmo que isso seja insuficiente), conforme, no Brasil, igualmente propugnou Luiz Roberto Barroso e, há mais tempo, Paulo Bonavides.

Para além disso, como dito, há ainda a celeuma da procedimentalização do direito no mundo globalizado, essencialmente neoliberal. $O$ que não são as normatizações e procedimentalizações no berço da União Europeia senão a ideia de fundação, institucionalização e limitação de um poder político extra-estatal, numa espécie de neoconstitucionalismo.

A forma jurídica, que é moderna, apesar de aparecer nos discursos jurídicos "pós-modernizantes" como algo novo - todos os tipos de "neo(s)" neopositivismo, neonormativismo, neoconstitucionalismo etc. - ainda está adstrita aos mesmos padrões capitalistas que a ligava à forma mercadoria, porém, é certo, com outra roupagem ideológica que não mais somente aquela própria ao modelo fordista, de respostas positivistas técnicas e padronizadas, no seio de instituições secularmente criadas.

Segurança jurídica, propriedade privada, direitos e garantias individuais, divisão dos poderes, federalismo, competência, soberania e tantos outros grandes temas do direito moderno se mantêm na prática e no discurso jurídico, seja para o bem de todos e algum progresso social da coletividade, ou seja, para o mal dessa mesma sociedade. Ou são os neoliberalismos e os conservadorismos a se imporem nas construções normativas e constitucionalizantes ou mesmo (des)normativas e (des)constitucionalizantes - o que parece ser o mote pós-moderno - ou, para o bem, existe um resquício de Estado social e políticas sociais a proclamarem, em alguma medida, a igualdade social e a dignidade humana.

O tema das decisões legítimas nas democracias europeias não pode ser o único norte de preocupação na constitucionalização de um dito Estado europeu ou na criação e aperfeiçoamento de um direito global - pautas, diga-se en passant, que atendem somente aos reclamos neoliberais.

\footnotetext{
${ }^{2}$ Vide Ferdinand Lassalle, A Essência da Constituição. $6^{\mathrm{a}}$ ed., Rio de Janeiro: Editora Lumen Juris, 2001.
} 
Para o direito, é certo que no caso da União Europeia existe um problema latente de procedimentalização. As mais diversas celeumas surgem na aplicação e interpretação do direito supranacional em face dos limites das soberanias dos Estados constituídos. Pode-se defender uma Constituição europeia pela partilha da cidadania entre os Estados nacionais constituídos e o modelo pós-estatal a constituir-se. Entretanto, superando esse problema e alguns outros que seguem nesse sentido, apontados, por exemplo, por Habermas, no texto Um ensaio sobre a Constituição da Europa, entende-se que a constitucionalização para a Europa não encontra o grande nó (pelo menos social) na procedimentalização normativa. Não se trata apenas de focar as teorias democráticas e federalistas. Até onde há o respeito ao consenso democrático, ou mesmo, até onde esse consenso é legítimo ou, para as teorias federalistas, até onde alcança efetividade normativa territorial as normas supranacionais? O problema não é da falta de democracia, mas de qual democracia se está a falar. No caso da União Europeia, uma democracia somente de cunho formal que respeita as "razões dos mercados".

Essa democracia atual, defendida pelas vozes do neoliberalismo, não resgata necessariamente os diversos aspectos e acepções do conceito democrático - rico, em algum sentido, do ponto de vista cultural e social (mas também bárbara ${ }^{3}$ ) -, antes é um reducionismo imoral dos problemas sociais às decisões consensuais formais de pequenos grupos que representam nações inteiras e que, obscuramente ou não, estão pautados em demandas privadas.

O tema atual da máxima integração jurídica e procedimental da União Europeia não está de soslaio aos interesses econômicos que orientam a construção dos arcabouços jurídicos modernos. A matriz da segurança jurídica e da propriedade privada é mantida com toda a força institucional, mas a modernidade jurídica, em outros aspectos, é esquecida, apagada. Mesmo sabendo que a forma jurídica equivale à forma mercadoria ${ }^{4}$, houve tempos de certos avanços sociais no campo normativo, mesmo que fossem como uma espécie de contrapeso aos interesses do capital. Vive-se atualmente em uma época histórica na qual os ganhos institucionais e normativos são menos quantitativos e qualitativos do que já foram. A dignidade da pessoa humana ${ }^{5} \mathrm{e}$ a realização dos direitos sociais devem ser dilemas modernos a serem resgatados, sem esquecer-se que o direito é fruto da sociabilidade capitalista, determinado, em última instância, nos aparelhos ideológicos de Estado ${ }^{6}$.

Entretanto, com o avanço do neoliberalismo em escala mundial, rompendo com as próprias estruturas modernas dos Estados soberanos, é provável que a retomada de princípios jurídicos de alta carga axiológica - como p. ex. a dignidade da pessoa humana -, por um Tribunal Constitucional Internacional, possa contrabalancear o eixo do debate jurídico-político, propiciando maior amplitude de diálogos. Com base em princípios jurídicos mais universais, como é o caso exemplar da dignidade da pessoa humana, um Tribunal Constitucional Internacional teria, assim, uma atuação - em termos de conteúdo jurídico - muito mais ampliada, pois

\footnotetext{
${ }^{3}$ Lembra-se aqui Walter Benjamin: "Não há nenhum documento da cultura que não seja também documento de barbárie. E é a mesma barbárie que os impregna, que impregna também os processos da sua transmissão". BENJAMIN, Walter. Sobre Arte, Técnica, Linguagem e Política. Lisboa: Relógio D’Água, 2012, p. 134.

4 Sobre a equivalência da forma jurídica à forma-mercadoria vide: NAVES, Márcio Bilharinho. Marxismo e Direito: um estudo sobre Pachukanis. São Paulo: Boitempo, 2008 e PASUKANIS, E. B. A Teoria Geral do Direito e o Marxismo. Rio de Janeiro: Renovar, 1989.

5 Ernst Bloch aponta um valor crítico para a dignidade da pessoa humana. Acerca do direito e da dignidade da pessoa humana em Ernest Bloch vide MASCARO, Alysson Leandro. Utopia e Direito: Ernst Bloch e a Ontologia Jurídica da Utopia. São Paulo: Quartier Latin, 2008.

${ }^{6}$ Para aparelhos de Estado e determinação do direito em última instância vide ALTHUSSER, Louis. Aparelhos Ideológicos de Estado. Rio de Janeiro: Edições Graal, 1985.
} 
com dilatada possibilidade de fundamentação humanista ${ }^{7}$, em uma dimensão universalista ${ }^{8}$, em complemento as instituições dos países membros.

Colocar a questão da dignidade da pessoa humana como um dos núcleos de fundamentação de um Tribunal Constitucional Internacional significa para além de sua ligação com as Constituições, o constitucionalismo ou os direitos humanos demarcar novamente a sua posição "como parâmetro regulador da intervenção", in caso, de um órgão judicante constitucional internacional com ampla representatividade ${ }^{9}$.

A inspiração do órgão judicante constitucional internacional no princípio da dignidade da pessoa humana é possível, pois esse vetor fundamental, nascido na modernidade tardia, é, em termos hermenêuticos, teto piramidal da cadeia normativa. Trata-se de um princípio jurídico de cunho nacional e internacional, de relação direta com a superação da discriminação e da intolerância, com a integração dos povos e com a igualdade material, essa no combate à exclusão social ${ }^{10}$.

Com os riscos que acompanham as institucionalizações, igualmente algo de mais acabado senão de melhor pode suceder. Do seio do pensamento moderno, parece que a teoria dos freios e contrapesos deve ser revalidada na União Europeia. Um Tribunal Constitucional Internacional ${ }^{11}$ poderia ter a tarefa, senão de interpretar

\footnotetext{
${ }^{7}$ Sobre a ampla possibilidade de fundamentação da dignidade humana, pelo seu caráter aberto: "Como imperativo filosófico, o princípio da dignidade da pessoa humana carece de ser continuamente reafirmado e densificado. Na verdade, estamos perante uma noção aberta e relativamente indeterminada que carecerá, em cada momento, de ser preenchida. Esta ausência de um conteúdo preciso (definível), ao invés de uma característica debilitante, confere ao princípio, uma efectiva dimensão operatória e um específico potencial dinâmico - actualista muito próximo das noções de conteúdo variável ('ordem pública', 'bons costumes', 'sociedade democrática', etc.)". MARQUES, Mário Reis. A Dignidade Humana como Prius Axiomático. Coimbra: Coimbra Editora, 2010, p. 565.

8 Acerca da perspectiva universalista da dignidade da pessoa humana: "Não é esta a ocasião para avaliarmos se não estaremos perante um verdadeiro 'universal transcultural', isto é, perante algo que, sendo compatível com a relatividade cultural e com as inevitáveis dissensões discursivas, sem que atinja a dimensão do absoluto, possa usufruir de um consenso global empiricamente demonstrável, embora vivenciado a partir de diversas intensidades. O certo é que a dignidade humana se globalizou, transcendendo, em termos de 'vinculação espacial', os seus confins originários. Verdadeiro princípio de direito internacional, a dignidade da pessoa humana impõe-se à escala mundial como uma verdadeira síntese valorativa civilizacional. A sua consagração globalizada investe-a numa 'espécie de princípio geral comum a todas as nações civilizadas' ou num ' verdadeiro princípio universal do direito contemporâneo". MARQUES, Mário Reis. A Dignidade Humana como Prius Axiomático. Coimbra: Coimbra Editora, 2010, p. 556-557.

9 Referente à institucionalização da dignidade da pessoa humana: “A dignidade, para além de surgir intimamente relacionada com os direitos humanos, impõe-se como padrão genérico de actuação e como parâmetro regulador da intervenção dos poderes públicos". MARQUES, Mário Reis. A Dignidade Humana como Prius Axiomático. Coimbra: Coimbra Editora, 2010, p. 552.

${ }_{10}$ Vide Luís Roberto Barroso: "A dignidade relaciona-se tanto com a liberdade e valores do espírito quanto com as condições materiais de subsistência. O desrespeito a esse princípio terá sido um dos estigmas do século que se encerrou e a luta por sua afirmação, um símbolo do novo tempo. Ele representa a superação da intolerância, da discriminação, da exclusão social, da violência, da incapacidade de aceitar o outro, o diferente, na plenitude de sua liberdade de ser, pensar e criar." BARROSO, Luís Roberto. Curso de Direito Constitucional Contemporâneo: os conceitos fundamentais e a construção do novo modelo. São Paulo: Saraiva, 2010, p. 274.

11 No campo jurídico, o juspublicista Paulo Ferreira da Cunha aparece como um dos principais interlocutores na defesa da criação de um Tribunal Constitucional Internacional. Por outro lado, no campo político, a ideia de criação do Tribunal Constitucional Internacional passa pelos países árabes. Observa Amarah Farrage, no artigo intitulado Tribunal Constitucional Internacional: desafios de uma nova realidade: "Esta ideia surgiu do seio do processo de revolução democrática que vem passando nos países árabes. Moncef Marzouki, então presidente da Tunísia (2011-2014), requisitou a criação deste tribunal onde as ideias inspiradoras estão num livro intitulado The Arab Pain. No meio deste processo, foi criado um comité especializado para a promoção da ideia e delineamento deste tribunal, no sentido de conseguirem apoio não só das Nações Unidas, mas de outros países que ainda não estão envolvidos nesse contexto." FERRAGE, Amarah. Tribunal Constitucional Internacional: desafios de uma nova realidade. Revista Incomunidade. Ano 3. Edição 33, abril.
} 
coativamente a normas supranacionais e os Tratados, pelo menos integrar em caráter de orientação o direito constitucional global ${ }^{12}$, na esteira da globalização e para além seus ideários neoliberais, a espera de um projeto social mais comum aos países interlocutores, ou no regresso dessa globalização perversa, ao retorno de viáveis projetos sociais aos Estados nacionais "soberanos".

Entretanto, um Tribunal Constitucional Internacional só poderia ter algum relevante peso no jogo político e geopolítico internacional caso constituído fosse por representantes heterogêneos dos países membros, abrindo-se oportunidades para a sua formatação por países dos cinco continentes, incluindo representantes do hemisfério sul menos desenvolvido, todos com os mesmos direitos deliberativos e decisórios.

Pelo direito, somente com novas institucionalizações que consideram a participação ativa da periferia do globo poderão suceder alguns ganhos sociais, seja para os países que vivem mesmo sem quase nenhuma institucionalização e normatização moderna (a exemplo de boa parte do continente africano), ou seja, para os países nos quais as lutas sociais perdem espaços para os interesses neoliberais.

\section{II - O Tribunal Constitucional Internacional e a Modernidade: a continuidade das Razões Estatais da Modernidade Jurídica}

O projeto de um Tribunal Constitucional Internacional aponta para o resgate de valores liberais da modernidade jurídica ${ }^{13}$. Contra o choque da pós-modernidade do capitalismo financeiro, a volta aos valores jurídicos da modernidade jurídica liberal acaba por ser mais progressista. Contra o juspositivismo ético pós-moderno do neoconstitucionalismo liberal muito melhor é o retorno aos valores do juspositivismo estrito do constitucionalismo liberal e/ou social do pós-guerra da primeira metade do século XX, onde mais bem definidas estavam as pautas progressistas e conservadoras $^{14}$. O direito moderno, em contraposição à soberania dos Estados

\footnotetext{
12 A retomada de um projeto moderno ao direito haveria de surtir mais efeitos se tomando como referência o direito constitucional, principalmente por ser esse o ramo do direito mais próximo da ciência política, a exemplo do que lembra Paulo Bonavides, ao citar os autores que a isso fazem referência: "A ênfase foi posta, aliás, nas instituições políticas, ao lado de cuja designação sói aparecer o Direito Constitucional. Trabalhos de Duverger, Prélot e Burdeau assinalam a sobredita tendência ou diretriz, que parece atar, definitivamente, nos compêndios, o Direito Constitucional à Ciência Política. Dentre os publicistas de língua portuguesa representativos daquela mesma posição figura, sem dúvida, Marcello Caetano, cujo tratado - Curso de Ciência Política e Direito Constitucional - surge também vazado naquela linha nova de compreensão e exposição dos temas políticos." BONAVIDES, Paulo. Curso de Direito Constitucional. São Paulo: Malheiros, 2003, p. 49.

${ }^{13}$ A modernidade jurídica é um tempo amplo para o direito, muito contrário das ideias defendidas de uma pós-modernidade jurídica. Referente à modernidade jurídica, Paulo Ferreira da Cunha elabora uma síntese: "Numa síntese das sínteses, a modernidade jurídica crê na coercividade do Direito, majoritariamente diviniza a lei, produto da democrática vontade geral (em várias versões), isto é, produto político do poder; por vezes, crê mais diretamente na Sociedade e nas práticas socialmente instituídas ou aprovadas; a espaços, adere a uma mística histórica e à ideia de um direito de classe; mais raramente, invoca a moral e grandes princípios apriorísticos inscritos num grande livro no céu”. CUNHA, Paulo Ferreira da. Pensar o Direito II: Da Modernidade à Postmodernidade. Coimbra: Almedina, 1991, p. 52.

${ }^{14}$ Igualmente, nesse sentido, uma passagem de Alysson Mascaro reflete a mudança de paradigma político entre o velho constitucionalismo e o novo constitucionalismo: "E, além disso, o propalado avanço político do jurista, a partir do Neoconstitucionalismo, pode se revelar uma arma nova e potente em serviço do conservadorismo político. $\mathrm{O}$ velho juspositivismo estrito, limitado e rígido em suas possibilidades, prestase a ser objeto de combate de modo mais claro que o neoconstitucionalismo, cujo espaço de atuação numa zona cinzenta do possível torna a ação política mitigada e contida num jogo de ganhos provisórios e pequenos para todos os lados. $\mathrm{O}$ velho constitucionalismo, juspositivista, determina mais e permite mais clareza até na oposição política. O neoconstitucionalismo aglutina os opostos num jogo de confluência principiológica que, no limite, é também conservador, mas sem abrir margem à oposição estrutural." MASCARO, Alysson Leandro; FRANCISCO, José Carlos (Coord.). Neoconstitucionalismo e atividade jurisdicional: do passivismo ao ativismo judicial. Belo Horizonte: Del Rey, 2012. p. 44.
} 
diluídos nos blocos econômicos, tinha como mote o instrumental da lei forte, com o Estado centralizador. ${ }^{15}$ Nesse sentido, a soberania é muito mais um conceito moderno, que haveria de ser retomado no resguardo dos direitos sociais e da dignidade da pessoa humana, nestes tempos de retração dos ganhos sociais tendo em vista às imposições do capital financeiro e das grandes multinacionais.

Se os direitos humanos e muitos outros tópicos axiológico-jurídicos da modernidade têm pés nos ideais liberais, é correto - há que se dizer - que aqueles, igualmente, são apropriados, quando da universalização da sua defesa, por movimentos e teóricos progressistas ${ }^{16}$, o que permite, em ultima ratio, a defesa das instituições e grupos que buscam universalizá-los.

A União Europeia, em especial a UEM, quando, com a imposição da moeda única deixa de lado as políticas monetárias dos Estados-nação, impondo as políticas de austeridade fiscal, com a consequente diminuição dos direitos sociais, rompe a mais legítima soberania ${ }^{17}$ e cidadania ${ }^{18}$, valores nascidos da modernidade jurídica ${ }^{19}$, do modo de produção capitalista.

15 Para esse sentido de modernidade jurídica: "O espírito da modernidade, tendo desembocado na ideologia da lei forte, aliada à unidade do Estado moderno centralizador, às doutrinas da exegese literal do direito (Escola Pandectista, Escola da Exegese, Escola da Jurisprudência dos Conceitos) e à fundamentação do direito no espírito positivo e empírico de seu tempo, caminha no sentido da valorização de aspectos técnicos, operacionais, conceituais e sistêmicos do direito". BITTAR, Eduardo C. B. O Direito na Pós-Modernidade. São Paulo: Forense Universitária, 2005, p. 181-182.

${ }^{16}$ Vide Boaventura de Souza Santos: "O objetivo de adotar declarações internacionais e de regimes e instituições internacionais de direitos humanos visa garantir mínimos de dignidade aos indivíduos sempre e quando os direitos de pertença a uma coletividade política não existissem ou fossem violados." e "Mas a verdade é que a efetividade da proteção ampla dos direitos de cidadania foi sempre precária na grande maioria dos países. E a evocação dos direitos humanos ocorreu sobretudo em situação de erosão ou violação particularmente grave dos direitos de cidadania". SANTOS, Boaventura de Souza. Direitos Humanos democracia e desenvolvimento. São Paulo: Ed. Cortez, 2014, p. 50.

${ }^{17}$ Existe um problema real de legitimidade da soberania na União Europeia. Nesse sentido: "Porque a União Europeia não é um estado federal - e acreditamos que os seus povos não querem sê-lo -, a soberania nacional retirada aos estados membros não foi transferida para nenhuma instância comunitária: não há um governo comunitário, não há uma política económica comum, nem uma política orçamental nem uma política fiscal comum, e a política monetária única está completamente desfasada da realidade da grande maioria dos países que integram a união monetária”. NUNES, António Avelãs. Uma leitura crítica da actual crise do capitalismo. Coimbra: FDUC, 2010, p. 80-81. Também: "A promiscuidade crescente entre o poder político e o poder econômico, a hipertrofia das funções de acumulação do Estado em detrimento das funções de confiança e de hegemonia, as condicionalidades impostas por agências financeiras internacionais, o papel preponderante das empresas multinacionais na economia mundial, a concentração da riqueza, tudo isto tem contribuído para reorganizar o Estado, diluindo a sua soberania, submetendo-o à crescente influência de poderosos atores econômicos nacionais e internacionais, fazendo com que os mandatos democráticos sejam subvertidos por mandatos de interesses minoritários mas muito poderosos." SANTOS, Boaventura de Souza. Direitos Humanos democracia e desenvolvimento. São Paulo: Ed. Cortez, 2014, p. 51-52.

18 “(...) a União Europeia, ao limitar dramaticamente os direitos econômicos e sociais dos cidadãos, aceita o sequestro da democracia pelo capital financeiro internacional, enquanto os cidadãos, atônitos ante a irrelevância dos seus direitos políticos sobre as instituições democráticas, descobrem na rua o único espaço público ainda não colonizado pelos mercados. Aí exercem esses direitos à beira do desespero e desprovidos de formulação política alternativa". SANTOS, Boaventura de Souza. Direitos Humanos democracia e desenvolvimento. São Paulo: Ed. Cortez, 2014, p. 67.

19 "No que se refere à zona do euro, a política monetária única serve apenas o objetivo de garantir a estabilidade dos preços, e as receitas neoliberais, nomeadamente a que se traduz na independência dos bancos centrais, retiraram aos estados possibilidade de se financiarem através da emissão de moeda. Ao menos para os estados mais fracos, é, verdadeiramente, a privatização do estado, colocando os estados nacionais na mesma situação de qualquer particular: quando precisam de dinheiro, vão aos mercados e estes é que decidem se concedem crédito ou não (e em que condições), decidindo, em último termo, o que convém ou não convém ao país, apesar de não terem nenhum mandato democrático para o exercício dessa função de gestores da res publica". NUNES, António Avelãs. Uma leitura crítica da actual crise do capitalismo. Coimbra: FDUC, 2010, p. 80-81. 
A verdade de um Tribunal Constitucional Internacional deve ser a verdade da modernidade jurídica, do retorno ao discurso moderno do direito, desacelerando o menoscabo aos valores soberanos dos Estados ${ }^{20} \mathrm{e}$ da "dignidade" dos povos frente aos interesses financistas. Mas, não menos verdade é o duplo risco de criação de um Tribunal Constitucional Internacional. Não há meio termo, ou o Tribunal Constitucional Internacional significará um retorno à modernidade jurídica em uma linha progressista de proteção positiva dos direitos humanos ${ }^{21}$ e da dignidade da pessoa humana ou, no exato contrário, é o mais bem acabado reflexo dos ideais jurídicos pós-modernos, tais como a descentralização dos Estados-nacionais, a prevalência de um direito fluído e de um discurso jurídico sofista de defesa da ética e da democracia na preservação somente dos interesses do capital.

\section{III - Conclusão. Política, Direito e Forma-Mercadoria: O Tribunal Constitucional Internacional como uma Questão Política}

Política, direito e mercadoria são conceitos que andaram e andam juntos na história da humanidade. A universalização da forma mercadoria requereu (e isso estruturalmente) uma forma política estatal normativa, que fosse capaz de dar conta da sua equivalência à forma jurídica ${ }^{22}$. $\mathrm{O}$ direito se apresenta na modernidade como expressão de interesse dos detentores do capital e, nisso, a globalização jurídica só veio a confirmar, o que, a passos largos, a teoria materialista do direito e do Estado sempre apontou. Nas crises econômicas e sociais graves, a política comunitária não é central e tudo se resolve no âmbito dos interesses neoliberais levados adiantes institucionalmente pelos governos. ${ }^{23}$ Nesse sentido, a forma-jurídica aparece inexoravelmente como o instrumental institucional mais estrutural do capitalismo e das políticas neoliberais, deixando migalhas de espaços para as políticas sociais não institucionalizadas ${ }^{24}$.

A política econômica da União Europeia é um evidente exemplo de que o direito e o Estado gozam de autonomia muito relativa frente aos interesses capitalistas. Não só na periferia do globo, mas, igualmente, no berço da civilização acidental

\footnotetext{
20 "À escala europeia, a soberania dos estados nacionais (a política soberana) deixou de contar (ao menos para os estados mais débeis) e a soberania da União não existe." NUNES, António Avelãs. Uma leitura crítica da actual crise do capitalismo. Coimbra: FDUC, 2010, p. 82.

${ }^{21} \mathrm{O}$ sentido de direitos humanos acusado aqui é na linha da evolução histórica lembrada por Boaventura de Souza Santos: "Com a emergência gradual dos direitos humanos sociais e econômicos, a exigência ante o Estado deixou de ter um caráter negativo para passar a ter um caráter positivo (o Estado deve agir de modo a realizar as prestações em que se traduzem os direitos). Por uma outra via, o Estado tem permanecido no centro dos debates sobre os direitos humanos e assim deve continuar." SANTOS, Boaventura de Souza. Direitos Humanos democracia e desenvolvimento. São Paulo: Ed. Cortez, 2014, p. 50-51.

22 Para essa temática vide: MASCARO, Alysson Leandro. Estado e Forma Política. São Paulo: Boitempo, 2013. HIRSCH, Joachim. Teoria Materialista do Estado: processos de transformação do sistema capitalista de Estado. Trad. De Luciano Cavini Martorano. Rio de Janeiro: Revan, 2010.

${ }^{23}$ Nesse sentido: "Em caso de crise grave (especialmente nos países mais débeis), não há, como estamos a ver, políticas comunitárias que possam ser mobilizadas para a ultrapassar. Antes pelo contrário: desde a eclosão da crise, tudo se resolve (ou nada se resolve) no âmbito das relações inter-governamentais, segundo a correlação de forças reinante. Durante a preparação da UEM, chegou a ser proposto um esquema baseado na transferência de verbas do orçamento comunitário para ajudar (sobretudo) os pequenos países afetados por choques externos (v.g. uma baixa significativa das exportações) a desencadear políticas destinadas a ultrapassar a crise. Esta solução não foi adotada, tendo-se sacrificado a economia real e a solidariedade comunitária aos equilíbrios financeiros. NUNES, António Avelãs. Uma leitura crítica da actual crise do capitalismo. Coimbra: FDUC, 2010, p.74-75.

${ }^{24}$ Em relação à política não institucionalizada: "O Estado é apenas um dos lugares - e ainda muitíssimo significativo, por enquanto ao menos - mas apenas um dos lugares em que se exerce a política. Mas interessantes e realmente mais fecundas são as perspectivas que alargam a política para além dos limites do Estado". CUNHA, Paulo Ferreira. Política Mínima. Coimbra: Almedina, 2005, p. 56.
} 
moderna, o neoliberalismo, nas suas imposições instrumentais e ideológicas, desconsidera os ganhos dos direitos sociais.

"Resultado: dentro da lógica da UEM, a estes últimos países, quando afetados por crises graves, só resta acatar a ortodoxia monetarista, que impõe o sacrifício do crescimento económico, o aumento do desemprego, a privatização das empresas públicas (ainda por cima a preços vis), a redução do investimento público, o congelamento ou a diminuição de salários e pensões de reforma e a redução dos direitos sociais dos trabalhadores ${ }^{25}$ ".

Assim como em um plano estrutural maior, no qual a forma jurídica equivale à forma mercadoria - particularmente porque "o circuito das trocas exige a mediação jurídica, pois o valor de troca das mercadorias só se realiza se uma operação jurídica - o acordo de vontade equivalentes - for introduzida"26 -, nas relações políticas estatais, o direito institucionaliza as políticas neoliberais, precisamente quando essas se equivalem a forma política estatal, sendo o neoliberalismo a expressão contemporânea do capitalismo. Atuando nesse movimento, direito e política têm a função (que é moderna) de igualizarem formalmente os Estados, sem considerar a ínsita desigualdade econômica e social desses. Portanto, a forma-estatal, como um correspondente da forma jurídica, planifica as relações, deixando muito pouco espaço para avanços sociais. Ou seja, para não se ter ilusões e querer-se demais quanto às possibilidades progressistas do direito, não se deve abandonar a consideração de sua estrutural relação com a forma-mercadoria. Entretanto, ainda assim é possível viabilizar alguns ganhos sociais quando se defende os direitos sociais contra as políticas neoliberais.

Por outro lado, os maiores ganhos sociais, na sociabilidade capitalista, ainda aparecem pela política, institucionalizada ou não. Significativos ganhos sociais na norma, portanto, em ultima ratio, encontram resistência na própria estruturação da sociedade capitalista, tendo, por isso, limites precisos e delimitados: a forma-capital.

A ideia de criação de um Tribunal Constitucional Internacional, como um órgão institucional internacional na defesa dos direitos humanos, dos direitos sociais e da dignidade da pessoa humana nesses tempos de predomínio do neoliberalismo, deve ser encarada como uma questão essencialmente política. Só a politização do jurídico será capaz de orientar uma "atuação judiciária” em defesa dos direitos sociais, sem, contudo, é certo, sanar as grandes celeumas estruturais do modo de produção capitalista - insanáveis pelo direito.

Em tese, para contrabalancear o debate político neoliberal e, também, definir pautas, a institucionalização de um Tribunal Constitucional Internacional deverá assentar-se em valores políticos progressistas. Daí, igualmente, não é demais lembrar, a necessidade da composição do Tribunal Constitucional Internacional ser paritária, e com a presença de diversos países periféricos, mais pobres, como integrantes, com direito igual de voto. Um Tribunal Constitucional Internacional que fosse composto por países centrais - àqueles responsáveis pelas decisões econômicas mais importantes do mundo - só faria engrossar os interesses desses Estados dominadores em detrimento dos países submissos.

\footnotetext{
${ }^{25}$ NUNES, António Avelãs. Uma leitura crítica da actual crise do capitalismo. Coimbra: FDUC, 2010, p. 74-75.

${ }^{26}$ NAVES, Márcio Bilharinho. Marxismo e Direito: um estudo sobre Pachukanis. São Paulo: Boitempo, 2008. p. 57.
} 
O projeto de um Tribunal Constitucional Internacional é um projeto ainda da modernidade jurídica, não só no seu sentido liberal, mas, sobretudo, no seu sentido específico de avizinhamento aos valores do Estado social, como um passo importante, porém, insuficiente, de compreensão progressista do direito contemporâneo.

\section{Bibliografia}

ALTHUSSER, Louis. Aparelhos Ideológicos de Estado. Trad. Walter José Evangelista; Maria Laura Viveiros de Castro. $10^{\mathrm{a}}$ ed., Rio de Janeiro: Edições Graal, 1985.

BARROSO, Luís Roberto. Curso de Direito Constitucional. São Paulo: Saraiva, 2013. BONAVIDES, Paulo. Curso de Direito Constitucional. 13a ed., São Paulo: Malheiros, 2003.

BENJAMIN, Walter. Sobre Arte, Técnica, Linguagem e Política. Trad. Maria Luz Moita et al. Lisboa: Relógio D’Água, 2012.

BITTAR, Eduardo C. B. O Direito na Pós-Modernidade. São Paulo: Forense Universitária, 2005.

CANOTILHO, José Joaquim Gomes. Direito Constitucional e Teoria da Constituição. $5^{\text {a }}$ ed., Coimbra - POR: editora Almeida, 2002.

CUNHA, Paulo Ferreira da. Política Mínima. $2^{\mathrm{a}}$ ed., Coimbra: Almedina, 2005.

Pensar o Direito II. Da Modernidade à Postmodernidade. Coimbra: Almedina, 1991.

DIAS, Sousa. Žižek, Marx \& Beckett e a democracia por vir. $1^{\text {a }}$ ed., Lisboa: Documenta, 2014.

FERRAGE, Amarah. Tribunal Constitucional Internacional: desafios de uma nova realidade. Revista Incomunidade. Ano 3. Edição 33, abril, 2015.

FRANCISCO, José Carlos (Coordenador e coautor). Neoconstitucionalismo $e$ atividade jurisdicional: do passivismo ao ativismo judicial. Belo Horizonte: Del Rey, 2012.

HABERMAS, Jürgen. Um ensaio sobre a Constituição da Europa. Lisboa: Almedina, 2012.

HIRSCH, Joachim. Teoria Materialista do Estado: processos de transformação do sistema capitalista de Estado. Rio de janeiro: Revan, 2010. 
LASSALLE, Ferdinand. A Essência da Constituição. 6a. Ed. Rio de Janeiro: Editora Lumen Juris, 2001.

MARQUES, Mário Reis. A dignidade humana como um prius axiomático. In ANDRADE, Manuel da Costa; ANTUNES, Maria João; SOUSA, Susana Aires de Estudos em Homenagem ao Prof. Doutor Jorge de Figueiredo Dias : Volume 4. Coimbra: Coimbra Editora, 2010.

MASCARO, Alysson Leandro. Utopia e Direito: Ernst Bloch e a Ontologia Jurídica da Utopia. São Paulo: Quartier Latin, 2008.

Estado e Forma Política. São Paulo: Boitempo, 2013.

NAVES, Márcio Bilharinho. A questão do Direito em Marx. $1^{\text {a }}$ ed., São Paulo: Outras expressões; Dobra Universitário, 2014.

. Marxismo e Direito: um estudo sobre Pachukanis. $1^{\mathrm{a}}$ ed., $1^{\mathrm{a}}$ reimpressão. São Paulo: Boitempo, 2008.

NUNES, António Avelãs. A Crise do Capitalismo: Capitalismo, Neoliberalismo, Globalização. $5^{\text {a }}$ ed., Lisboa: página a página, 2013.

. "Uma leitura crítica da actual crise do capitalismo" em boletim de ciências econômicas LIV, Coimbra, FDUC, 2011.

PASUKANIS, E.B. A Teoria Geral do Direito e o Marxismo. Rio de Janeiro: Renovar, 1989.

SANTOS, Boaventura de Sousa. A crítica da razão indolente: contra o desperdício da experiência. $6^{\mathrm{a}}$ ed., São Paulo: Cortez, 2007.

Et al. Direitos humanos, democracia e Desenvolvimento. São Paulo: Ed. Cortez, 2014.

Pela Mão de Alice: O Social e o Político na pós-modernidade. 12a ed., São Paulo: Cortez, 2008.

Recebido para publicação em 05-09-15; aceito em 02-10-15 